\title{
Estudo Morfométrico Comparativo de Populações de Rotylenchulus reniformis (Nemata: Rotylenchulinae) do Brasil*
}

\author{
Pedro L. M. Soares ${ }^{1}$, Jaime M. dos $\operatorname{Santos}^{2} \&$ Paul S. Lehman ${ }^{3}$ \\ 1,2Departamento de Fitossanidade, Faculdade de Ciências Agrárias e Veterinárias, UNESP, Campus de Jaboticabal, \\ CEP 14884-900, Jaboticabal, SP, fax: (016) 3202-3641, e-mail: pedrolms@ @otmail.com; ${ }^{3}$ Department of \\ Agriculture and Consumer Services, Division of Plant Industry, Entomology Nematology, \\ Plant Pathology. P.O. Box $147100 / 1911$ SW 34 ${ }^{\text {th }}$ Street, Gainesville, Florida 32614-7100, EUA
}

(Aceito para publicação em 07/02/2003)

Autor para correspondência: Pedro L. M. Soares

SOARES, P.L.M., SANTOS, J.M. dos \& LEHMAN, P.S. Estudo morfométrico comparativo de populações de Rotylenchulus reniformis (Nemata: Rotylenchulinae) do Brasil. Fitopatologia Brasileira 28:292-297. 2003.

\section{RESUMO}

Quarenta e oito populações de Rotylenchulus reniformis foram recuperadas de amostras de solo e raízes de diferentes culturas e inoculadas em diferentes plantas hospedeiras, mantidas em microparcelas no Departamento de Fitossanidade da UNESP/ FCAV, Campus de Jaboticabal, São Paulo. Os sintomas da doença causada pelo nematóide em algodoeiro (Gossypium hirsutum), no campo, foram documentados, bem como o hábito de parasitismo do nematóide em raízes de algodão e de mamoeiro (Carica papaya), utilizando-se de coloração in situ do nematóide com fuccina ácida. Efetuou-se a comparação morfológica de todas as populações, ao microscópio óptico composto, em montagens temporárias e, de algumas, ao microscópio eletrônico de varredura. Para as observações ao microscópio eletrônico de varredura, fêmeas adultas presas às raízes foram fixadas em glutaraldeído e pós-fixadas em tetróxido de ósmio, desidratadas em álcool etílico, secas em secador de ponto crítico, montadas, recobertas com $35 \mathrm{~nm}$ de ouro, observadas e elétromicrografadas em $15 \mathrm{kV}$. Os dados obtidos confirmam que $R$. reniformis é a única espécie do gênero distribuída nos agroecossistemas brasileiros e que a amplitude de variação de caracteres morfométricos em populações brasileiras desse nematóide, tais como comprimento do estilete, $\mathrm{V} \%$ e forma da cauda, é maior que em populações da mesma espécie de outras regiões do mundo. Foram ilustradas fêmeas jovens de $R$. reniformis com a cauda bifurcada, e esse detalhe da morfologia do nematóide ainda não havia sido relatado.

Palavras-chave adicionais: taxonomia, nematóide reniforme, microscopia eletrônica de varredura, morfometria.

\section{ABSTRACT}

Comparative morphometric study of populations of Rotylenchulus reniformis (Nemata: Rotylenchulinae) from Brazil

Forty-eight populations of Rotylenchulus reniformis were obtained from soil and root samples of different crops and inoculated into various host plants grown in microplots at the Departamento de Fitossanidade of the Universidade Estadual Paulista, Campus de Jaboticabal, São Paulo, Brazil. The symptoms of the disease caused by the nematode in cotton (Gossypium hirsutum) plants were documented in field and the parasitic behavior of the nematode in roots of cotton and papaya (Carica papaya) plants were investigated by in situ staining of the nematode with acid fuchsin. All populations were studied with light microscopy in temporary mounts and some

\section{INTRODUÇÃO}

O gênero de nematóides Rotylenchulus engloba dez espécies semi-endoparasitos sedentários, com ampla distribuição em países tropicais e subtropicais (Fortuner, 1987; Lehman \& Inserra, 1990; Van Den Berg, 1990). Com efeito, Rotylenchulus reniformis (Linford \& Oliveira) encontra-se

\footnotetext{
*Parte da Dissertação do Trabalho de Graduação do primeiro autor (1999), desenvolvido com Auxílio à Pesquisa da FAPESP (Processo No. 99/ 04377-2).

${ }^{1}$ Bolsista IC-FAPESP
}

were also examined using scanning electron microscopy (SEM). For SEM, mature females attached to roots were fixed in buffered glutaraldehyde and post-fixed in osmium tetroxide. The samples were then dehydrated in ethanol, dried in a critical point dessicator, mounted, coated with a 35-nm layer of gold, examined and electronmicrographed at $15 \mathrm{kV}$. The data confirm that $R$. reniformis is the only species of the genus distributed in Brazil and based on data from the literature, the variations of the morphometric characteristics among $R$. reniformis Brazilian populations, such as stylet length, $\mathrm{V} \%$ and tail shape are greater than in populations of the same species from other parts of the world. Young females with bifurcated tails were documented in $R$. reniformis, a morphological feature that had not been previously reported. associado a mais de 140 espécies de plantas de mais de 115 gêneros de 46 famílias botânicas. Desta ampla gama de hospedeiros, 57 espécies são culturas de importância econômica (Jatala, 1991). Essa ampla faixa de hospedeiros é um fator limitante para a utilização da rotação de culturas como medida de manejo de populações desse nematóide e, considerando sua ampla distribuição em nossos agroecossistemas, constitui, também, uma limitação para a adoção dessa medida no manejo de outros nematóides, uma vez que essa prática pode reduzir a população da espéciealvo e aumentar a população de $R$. reniformis. 
Estudo morfométrico comparativo de populações de Rotylenchulus reniformis...

Durante muitos anos, o cultivo do algodoeiro (Gossypium hirsutum L.), no Estado de São Paulo, foi restrito às variedades da série IAC, resistentes a Meloidogyne incognita (Kofoid \& White) Chitwood. Essas variedades também foram largamente cultivadas em outras regiões do País, notadamente por possuírem resistência a esse nematóide. Contudo, as variedades da série IAC não são resistentes a $R$. reniformis. Com o passar dos anos, o rendimento da cultura do algodoeiro, no Estado de São Paulo, foi se tornando cada vez menor, até que se mudou a legislação, permitindo-se o plantio de outras cultivares a partir do final da década de 90 . Com efeito, $R$. reniformis é um dos nematóideschave da cultura do algodoeiro em todas as regiões produtoras do mundo (Starr \& Page, 1990).

Além dos danos diretos às raízes de seus hospedeiros, Rotylenchulus spp. interagem com outros patógenos, tais como Fusarium spp., Verticillium spp. e Rhizoctonia solani Kuhn, causando doenças complexas (Jatala, 1991).

Com base em caracteres morfométricos de fêmeas jovens, alguns pesquisadores propuseram chaves para a identificação das espécies de Rotylenchulus (Germani, 1978; Fortuner, 1987; Robinson et al., 1997). Nos EUA, Lehman \& Inserra (1990) estudaram duas populações de $R$. parvus Williams e nove de $R$. reniformis da região Sudeste e concluíram que as populações dessas duas espécies dos EUA podem ser facilmente separadas com base no comprimento do corpo, do estilete e da cauda de fêmeas imaturas. Com base na literatura pertinente, elaboraram um compêndio enfocando a variabilidade intra e interespecífica e uma chave para a identificação das espécies do grupo.

Embora sejam reconhecidas dez espécies válidas de Rotylenchulus (Lehman \& Inserra, 1990; Van Den Berg, 1990), no Brasil, todas as populações encontradas até o presente foram referidas como pertencentes a $R$. reniformis.

Este trabalho teve como objetivo o estudo morfométrico comparativo aos microscópios óptico e eletrônico de varredura de 48 populações de $R$. reniformis do Estado de São Paulo e de outras regiões do Brasil.

\section{MATERIAL E MÉTODOS}

Quarenta e oito populações de $R$. reniformis foram recuperadas de amostras de solo e raízes de diferentes regiões e culturas (Tabela 1) e inoculadas em diferentes plantas hospedeiras, mantidas em microparcelas do Departamento de Fitossanidade da UNESP/FCAV, Campus de Jaboticabal.

Os nematóides foram extraídos das amostras de solo pelo método da flotação centrífuga em solução de sacarose (Jenkins, 1964) e inoculados em plantas de algodoeiro cv. Deltapine 61, de tomateiro (Lycopersicon esculentum Mill.) cv. Santa Cruz Kada, de caupi (Vigna unguiculata L.) cv. Pitiúba, de mamoeiro (Carica papaya L.) cv. Formosa e de mamona (Ricinus communis L.).
TABELA 1 - Identificação, procedências e hospedeiros das populações de Rotylenchulus reniformis utilizadas no estudo

\begin{tabular}{|c|c|c|}
\hline $\begin{array}{l}\text { Identificação da } \\
\text { população }\end{array}$ & Procedência & Hospedeiro \\
\hline MP1 & Jaboticabal, SP & Tomateiro $^{1}$ \\
\hline MP2 & Jaboticabal, SP & Tomateiro \\
\hline MP3 & Miguelópolis, SP & Algodoeiro $^{2}$ \\
\hline MP4 & Jaboticabal, SP & Tomateiro \\
\hline MP5 & Riolândia, SP & Algodoeiro \\
\hline MP6 & Jaboticabal, SP & Mamoeiro $^{3}$ \\
\hline MP8 & Jaboticabal, SP & Mamoeiro \\
\hline MP9 & Jaboticabal, SP & Mamoeiro \\
\hline MP10 & Jaboticabal, SP & Mamoeiro \\
\hline MP11 & Miguelópolis, SP & Algodoeiro \\
\hline MP14 & Miguelópolis, SP & Algodoeiro/Soja \\
\hline MP16 & Ituverava, SP & Algodoeiro/Soja \\
\hline MP17 & Ituverava, SP & Algodoeiro/Soja \\
\hline MP18 & Ituverava, SP & Algodoeiro/Soja \\
\hline MP19 & Ituverava, SP & Algodoeiro/Soja \\
\hline MP20 & Ituverava, SP & Algodoeiro/Soja \\
\hline MP21 & Guaíra, SP & Algodoeiro \\
\hline MP22 & Jaboticabal, SP & Algodoeiro \\
\hline MP23 & Jaboticabal, SP & Algodoeiro \\
\hline MP25 & Riolândia, SP & Algodoeiro \\
\hline MP26 & Miguelópolis, SP & Algodoeiro \\
\hline MP27 & Miguelópolis, SP & Algodoeiro \\
\hline MP28 & Rondonópolis, MT & Algodoeiro \\
\hline MP29 & Rondonópolis, MT & Algodoeiro \\
\hline MP30 & Riolândia, SP & Algodoeiro \\
\hline MP35 & Ituverava, SP & Algodoeiro/Soja \\
\hline MP37 & Ituverava, SP & Algodoeiro \\
\hline MP39 & Miguelópolis, SP & Algodoeiro \\
\hline MP42 & Meridiano, SP & Soja \\
\hline MP43 & Santa Helena, GO & Algodoeiro \\
\hline MP44 & Mira Estrela, SP & Algodoeiro \\
\hline MP45 & Santa Helena, GO & Feijoeiro $^{5}$ \\
\hline MP47 & Santa Helena, GO & Algodoeiro \\
\hline MP49 & Itumbiara, GO & Algodoeiro \\
\hline MP51 & Santa Helena, GO & Algodoeiro \\
\hline MP52 & Santa Helena, GO & Feijoeiro \\
\hline MP55 & Santa Helena, GO & Soja \\
\hline MP58 & Santa Helena, GO & Soja \\
\hline MP62 & Santa Helena, GO & Soja \\
\hline MP63 & Itumbiara, GO & Feijoeiro \\
\hline MP64 & Santa Helena, GO & Algodoeiro \\
\hline MP65 & Santa Helena, GO & Algodoeiro \\
\hline MP67 & Ituverava, SP & Algodoeiro \\
\hline MP69 & Miguelópolis, SP & Algodoeiro \\
\hline MP70 & Guaíra, SP & Algodoeiro \\
\hline MPBA & Capela A. Alegre, BA & Maracujazeiro $^{6}$ \\
\hline MPAX & Vitória, ES & Abacaxizeiro $^{7}$ \\
\hline MPTY & Borborema, SP & Tomateiro \\
\hline
\end{tabular}

${ }^{1}$ Lycopersicon esculentum Mill., ${ }^{2}$ Gossypium hirsutum L., ${ }^{3}$ Carica papaya L., ${ }^{4}$ Glycine $\max$ (L.) Merril., ${ }^{5}$ Phaseolus vulgaris L., ${ }^{6}$ Passiflora edulis Sims., ${ }^{7}$ Ananas comosus (L.) Merr.

Para a inoculação de cada uma das plantas mencionadas, mudas foram produzidas em bandejas de poliestireno expandido de 128 células, em casa de vegetação, contendo substrato orgânico autoclavado. Uma muda de cada uma das espécies das plantas mencionadas foi transplantada para unidades de microparcelas, construídas com manilhas de cimento de $1 \mathrm{~m}$ de diâmetro e $1,2 \mathrm{~m}$ de altura, fincadas $1 \mathrm{~m}$ no solo a céu aberto. A cada 15 dias, $2 \mathrm{~g}$ da fórmula NPK1414-14 do fertilizante Osmocote ${ }^{\circledR}$ foram aplicados em cada 
microparcela, que foi irrigada em intervalos regulares de $48 \mathrm{~h}$. Quando algumas das plantas hospedeiras completavam o seu ciclo, uma nova planta da mesma espécie era transplantada para a microparcela correspondente.

\section{Estudo morfométrico comparativo de 48 populações de Rotylenchulus spp. ao microscópio óptico composto}

Após 180 dias da inoculação, juvenis, fêmeas jovens e machos foram recuperados de uma alíquota de $100 \mathrm{~cm}^{3} \mathrm{de}$ amostras de solo da rizosfera das plantas (Jenkins, 1964).

Fêmeas jovens foram utilizadas na preparação de montagens temporárias para fotomicrografias e mensurações em um sistema de aquisição de imagens, constituído por uma câmara digital SONY Hiper HAD, montada sobre um microscópio trinocular Olympus ${ }^{\circledR}$ BX50, acoplado a um computador Pentium 200. Foram medidos o comprimento dos estiletes e a posição da vulva, em percentagem do comprimento total do corpo (V \%) de 10 espécimes de cada uma das 48 populações. Os valores mínimo, máximo, a média e o desvio-padrão foram determinados para cada população estudada. A média dos valores do comprimento do estilete e de V (\%) de cada população foi submetida à chave dicotômica de Robinson et al. (1997).

\section{Coloração in situ de fêmeas de Rotylenchulus reniformis}

Raízes de algodoeiro e mamoeiro infetadas pelo nematóide foram processadas pela técnica de Byrd et al. (1983). Fêmeas adultas parcialmente imersas ou presas à superfície das raízes foram observadas e fotomicrografadas.

\section{Preparo de espécimes para a microscopia eletrônica de varredura}

Segmentos de raízes infetadas foram fixados em glutaraldeído a 3\%, em tampão de fosfato de potássio a 0,05 $\mathrm{M} \mathrm{e} \mathrm{pH} \mathrm{7,4} \mathrm{por} 72 \mathrm{~h}$. A seguir, foram lavados seis vezes consecutivas em solução tampão pura, em um intervalo de 15 min e pós-fixados em tetróxido de ósmio a $2 \%$, no mesmo tampão, por cerca de $12 \mathrm{~h}$. Posteriormente, foram novamente lavados como no caso anterior, desidratados em uma série gradual de álcool etílico $(30,50,70,80,90,95,100,100$ e $100 \%$ por 20 min cada), secos em secador de ponto crítico, utilizando-se de $\mathrm{CO}_{2}$, montados, metalizados com cerca de $35 \mathrm{~nm}$ de ouro-paládio, observados e elétromicrografados em microscópio eletrônico de varredura JEOL JSM 5410, operado em 15 kV (Santos \& Maia, 1997).

\section{RESULTADOS E DISCUSSÃO}

\section{Sintomas e sinais de Rotylenchulus reniformis}

Numa cultura de algodoeiro atacada, na região de Leme, SP, foram documentados os sintomas no campo que se apresentaram em forma de reboleira (Figura 1A), e referidos como "carijó" (Figura 1B) (Passos, 1977). O hábito semiendoparasita sedentário de $R$. reniformis (Jatala, 1991; Robinson et al., 1997) está ilustrado em raízes de algodão (Figura 1C e 1D). As fêmeas jovens podem ser vistas comple- tamente imersas nas raízes (Figura 1C), enquanto as fêmeas adultas usualmente são observadas com a parte dilatada do corpo externa à raiz e seus sítios de alimentação no cilindro central (Figura 1D). Em mamoeiro, foram observadas fêmeas adultas completamente externas às raízes, presas apenas pela placa labial. Nesses casos, seus sítios de alimentação situamse em células corticais (Figura 1E). De fato, Jatala (1991) fez menção a diferenças de comportamento desse nematóide em diferentes plantas hospedeiras. Uma massa de ovos de $R$. reniformis colorida in situ com fuccina ácida também pode ser observada (Figura 1F).

Uma fêmea adulta parcialmente recoberta pela sua massa de ovos foi ilustrada em raiz de mamona (Figura 2A). Ao microscópio eletrônico de varredura, observou-se que a massa de ovos tem o formato esférico e encerra tanto a fêmea quanto os seus ovos. De acordo com Sivakumar \& Seshadri (1971), a massa de ovos pode conter de 60 a 200 ovos. Fêmea com massa de ovos parcialmente removida e fêmea com massa de ovos totalmente removida (Figuras 2B e 2C) foram detectadas, possibilitando observar a inserção da região anterior do nematóide nos tecidos da raiz. Uma fêmea adulta, com a região anterior imersa nos tecidos da raiz, exibindo a vulva na região mediana da porção dilatada do corpo também foi eletromicrografada (Figura 2D).

\section{Estudo morfométrico de 48 populações de Rotylenchulus reniformis}

A forma de "C" característica do corpo vermiforme da fêmea jovem de $R$. reniformis (Figura 3A) e a posição da vulva, em relação à região labial, cuja distância em percentagem do comprimento total do corpo é definido como V \% (Figura 3A), enquanto outros caracteres morfológicos de interesse taxonômico relevante estão também indicados (Figura 3B). A DGO, definida como a distância entre a abertura da glândula dorsal esofagiana e a base do estilete, separa Rotylenchulus de outros gêneros de tilenquídeos. Os dados relativos às mensurações do comprimento do estilete e do valor de $\mathrm{V}(\%)$ de dez fêmeas jovens de cada uma das 48 populações estudadas foram anotados (Tabela 2). Esses dados, submetidos à chave proposta por Robinson et al. (1997), indicam que todas as populações estudadas pertencem a $R$. reniformis. A média geral para o valor de $\mathrm{V}$ $\%$ foi de 70,8 com amplitude de variação de 55,1 a 84,1. A média para o comprimento do estilete foi de 19,2 $\mu \mathrm{m}$ com amplitude de 11,6 a 27,8 (Tabela 2). O valor da média para V (\%), obtido da literatura, é de $71(67,0$ - 81,0) e do comprimento do estilete é de 17,2 $\mu \mathrm{m}(15,0$ - 21,0), conforme Lehman \& Inserra (1990). Conquanto tenha havido diferenças entre os valores máximos e mínimos para essas variáveis, os valores médios estão na faixa aceitável para $R$. reniformis, mesmo com o valor médio para o comprimento do estilete ligeiramente maior que o valor obtido na literatura, uma vez que, das espécies válidas, apenas $R$. macrodoratus (Dasgupta et al.) exibe tamanho médio do estilete maior [24,0 $\mu \mathrm{m}(22,0$ - 26,0)] que $R$. reniformis (Robinson et al., 1997).

A forma da região labial de fêmeas jovens de $R$. 

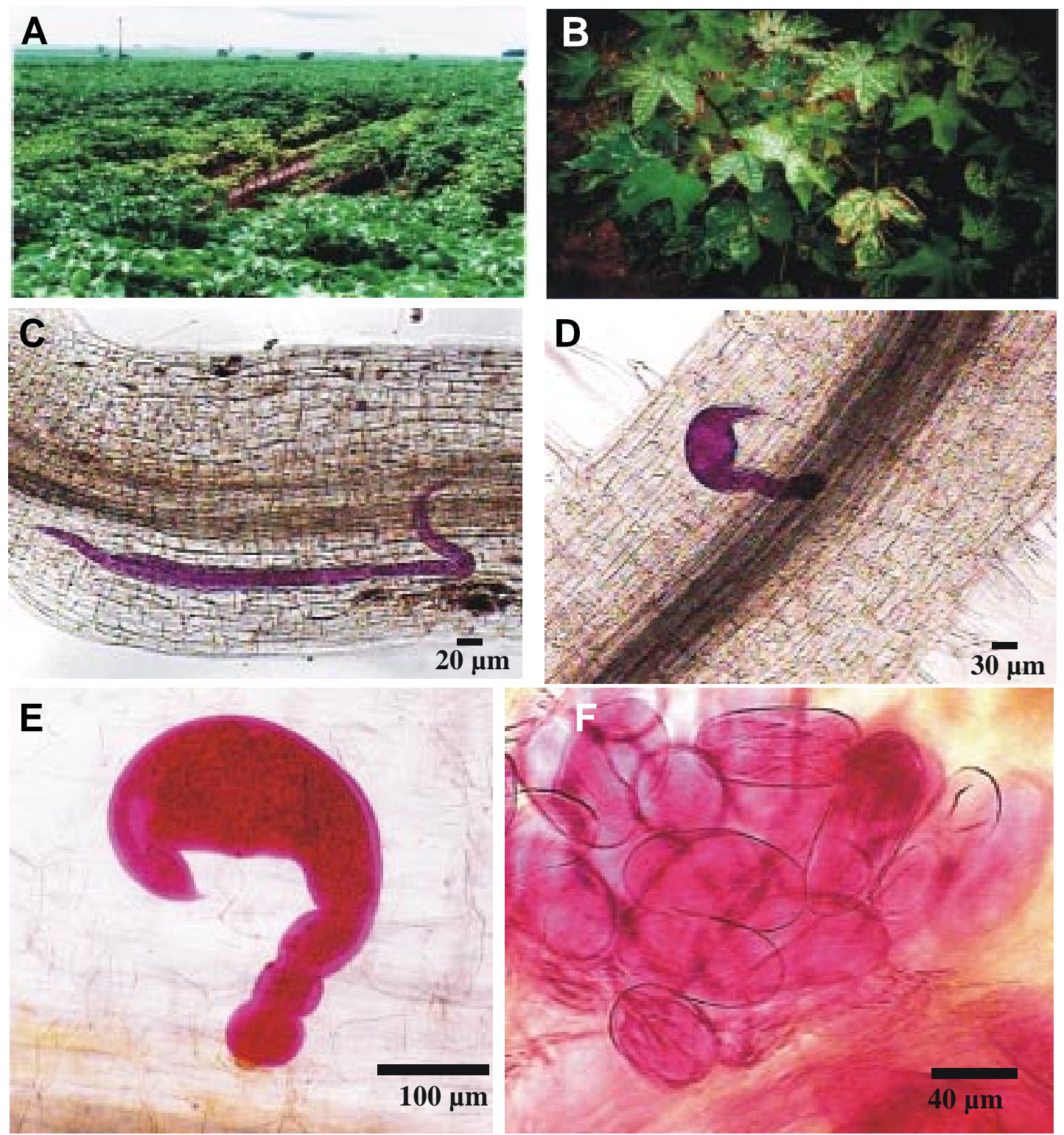

FIG. 1 - Sintomas da infecção e hábito de parasitismo de Rotylenchulus reniformis A) Reboleira resultante da infecção de $R$. reniformis em algodoeiro (Gossypium hirsutum); B) Sintoma "carijó" em plantas atacadas; C) Fotomicrografia de fêmeas jovens de R. reniformis imersas em raiz de algodoeiro; D) Fotomicrografia de uma fêmea adulta de $R$. reniformis com a região anterior no cilindro central e a porção dilatada do corpo externa à raiz; E) Fotomicrografia de uma fêmea adulta de $R$. reniformis externa à raiz de mamoeiro (Carica papaya) e F) Fotomicrografia de uma massa de ovos $R$. reniformis de clorida in situ com fuccina ácida.

reniformis, exibindo armadura cefálica acentuadamente esclerotizada, variou de alta, conóide e contínua com o corpo (Figura 4A) a arredondada (Figura 4B). Os nódulos basais do estilete voltados para trás (Figuras $4 \mathrm{~A}, \mathrm{~B}$ e C) constituem um caráter morfológico relevante para a identificação de $R$. reniformis (Siddiqi, 1972). A abertura da glândula dorsal esofagiana situa-se acerca de um comprimento do estilete, abaixo dos nódulos basais, conforme assinalado (seta) (Figura 4B), e essa distância entre as estruturas, referidas como DGO, separa o gênero de outros tilenquídeos. A região anterior de uma fêmea jovem com o metacorpo e a válvula esclerotizada (seta) também foi ilustrada (Figura 4C). A sobreposição ventral do esôfago sobre o intestino (setas) e a posição da abertura da glândula dorsal (seta) estão assinaladas (Figura 4D). O campo lateral de fêmeas jovens exibe quatro incisuras (Figura $4 \mathrm{E})$ e, freqüentemente, são encontradas fêmeas migradoras com cutículas remanescentes de ecdises anteriores, conforme assinalado em 4F (setas). Caudas afilando-se progressivamente com término arredondado (Figura 4G) ou bifurcada (Figura $4 \mathrm{H}$ ) foram observadas. O fasmídio (seta) em forma de poro (Figura 4I) está localizado na região mediana da cauda.

No presente estudo, comprovou-se que $R$. reniformis é a única espécie do gênero amplamente disseminada no 
P.L.M. Soares et al.

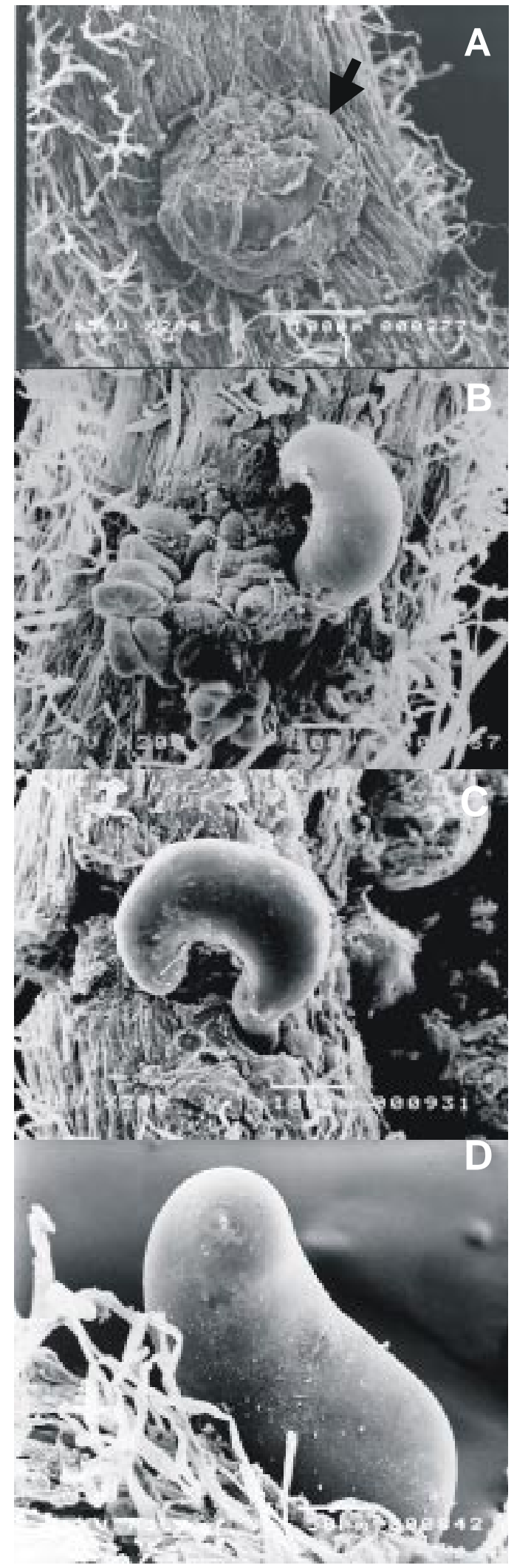

FIG. 2 - Elétromicrografias de varredura de fêmeas de Rotylenchus reniformis. A) Fêmea adulta dentre da massa de ovos; B) Fêmea adulta com a região anterior imersa na raiz; C) Fêmea adulta com a região anterior imersa na raiz; D) Fêmea adulta parcialmente imersa, exibindo a vulva.
TABELA 2 - Dados morfométricos de dez fêmeas jovens de cada uma das 48 populações de Rotylenchulus reniformis do Brasil

\begin{tabular}{|c|c|c|}
\hline $\begin{array}{l}\text { Identificação } \\
\text { da amostra }\end{array}$ & $\mathrm{V} \%$ & Estilete \\
\hline MP1 & $71,2^{\mathrm{a}}\left(68,1^{\mathrm{b}}-73,6^{\mathrm{c}}\right) \pm 1,6^{\mathrm{d}}$ & $20,3(16,9-22,5) \pm 1,9$ \\
\hline MP2 & $70,3(65,4-73,3) \pm 2,3$ & $18,0(16,8-20,0) \pm 1,1$ \\
\hline MP3 & $71,7(62,9-80,3) \pm 5,6$ & $20,0(17,9-23,9) \pm 2,1$ \\
\hline MP4 & $70,4(69,3-72,7) \pm 1,2$ & $17,9(15,8-17,9) \pm 0,7$ \\
\hline MP5 & $71,7(67,0-80,2) \pm 4,7$ & $20,7(17,3-24,9) \pm 2,7$ \\
\hline MP6 & $70,7(69,3-72,7) \pm 1,2$ & $17,1(15,8-17,9) \pm 0,7$ \\
\hline MP8 & $72,3(68,1-82,1) \pm 3,9$ & $19,0(15,8-25,00 \pm 2,8$ \\
\hline MP9 & $72,0(63,7-75,9) \pm 3,6$ & $20,6(18,5-23,8) \pm 2,0$ \\
\hline MP10 & $72,4(70,5-74,1) \pm 1,2$ & $16,9(15,6-17,8) \pm 0,8$ \\
\hline MP11 & $71,9(68,4-78,4) \pm 3,4$ & $16,2(14,4-18,2) \pm 1,4$ \\
\hline MP14 & $68,0(55,1-78,1) \pm 7,3$ & $18,3(14,0-23,0) \pm 2,5$ \\
\hline MP16 & $70,4(66,2-72,1) \pm 1,8$ & $16,6(11,6-20,6) \pm 2,6$ \\
\hline MP17 & $71,8(64,7-74,7) \pm 2,8$ & $17,6(15,6-25,0) \pm 2,9$ \\
\hline MP18 & $71,2(62,3-74,9) \pm 3,8$ & $20,6(15,0-23,8) \pm 2,8$ \\
\hline MP19 & $73,2(66,0-84,1) \pm 5,2$ & $17,1(13,4-19,6) \pm 1,6$ \\
\hline MP20 & $71,0(65,3-75,2) \pm 2,7$ & $18,1(15,2-23,5) \pm 2,4$ \\
\hline MP21 & $70,6(59,9-79,0) \pm 5,7$ & $20,4(17,9-22,5) \pm 1,6$ \\
\hline MP22 & $67,3(56,0-70,4) \pm 4,4$ & $20,5(17,5-23,6) \pm 2,0$ \\
\hline MP23 & $71,7(68,2-76,0) \pm 2,8$ & $18,9(16,6-22,8) \pm 2,2$ \\
\hline MP25 & $68,7(62,7-73,3) \pm 3,3$ & $20,5(16,7-25,0) \pm 3,1$ \\
\hline MP26 & $72,0(61,1-78,4) \pm 5,0$ & $21,3(17,5-24,8) \pm 2,8$ \\
\hline MP27 & $69,7(63,2-73,4) \pm 2,8$ & $18,0(17,0-20,0) \pm 1,0$ \\
\hline MP28 & $71,0(69,0-74,0) \pm 1,7$ & $20,7(16,9-23,8) \pm 2,4$ \\
\hline MP29 & $72,3(67,2-79,5) \pm 4,0$ & $21,1(17,3-25,0) \pm 2,5$ \\
\hline MP30 & $72,4(69,3-75,6) \pm 2,6$ & $20,5(17,3-24,4) \pm 2,3$ \\
\hline MP35 & $67,5(57,9-74,7) \pm 5,6$ & $20,1(15,3-25,0) \pm 3,3$ \\
\hline MP37 & $71,8(67,0-80,6) \pm 3,7$ & $20,4(13,4-25,0) \pm 3,3$ \\
\hline MP39 & $73,3(66,3-83,7) \pm 5,7$ & $17,8(14,0-23,1) \pm 2,9$ \\
\hline MP42 & $69,4(57,0-81,0) \pm 8,1$ & $18,7(13,8-23,8) \pm 2,8$ \\
\hline MP43 & $69,0(58,9-72,8) \pm 4,8$ & $17,4(16,0-18,8) \pm 0,9$ \\
\hline MP44 & $71,0(66,5-75,2) \pm 3,1$ & $20,0(14,1-22,5) \pm 2,7$ \\
\hline MP45 & $70,9(67,4-74,0) \pm 2,1$ & $18,8,(17,3-21,9) \pm 1,7$ \\
\hline MP47 & $71,1(68,1-74,6) \pm 1,7$ & $18,2(15,6-21,1) \pm 1,7$ \\
\hline MP49 & $70,7(67,9-75,2) \pm 2,3$ & $20,6(18,6-25,4) \pm 2,3$ \\
\hline MP51 & $70,0(68,7-72,9) \pm 1,3$ & $17,2(15,2-18,7) \pm 0,9$ \\
\hline MP52 & $69,1(64,0-75,7) \pm 3,9$ & $20,8(17,9-23,8) \pm 2,2$ \\
\hline MP55 & $70,8(68,2-77,3) \pm 2,8$ & $20,6(16,9-27,8) \pm 3,1$ \\
\hline MP58 & $68,6(58,7-75,4) \pm 5,3$ & $20,6(15,6-25,0) \pm 3,0$ \\
\hline MP62 & $69,8(66,8-73,5) \pm 1,8$ & $20,4(15,0-23,0) \pm 1,8$ \\
\hline MP63 & $72,4(59,6-80,3) \pm 6,5$ & $20,5(16,3-23,5) \pm 2,6$ \\
\hline MP64 & $70,0(64,0-74,2) \pm 3,0$ & $19,9(16,7-22,9) \pm 2,6$ \\
\hline MP65 & $71,9(68,8-74,4) \pm 1,7$ & $17,5(16,4-18,8) \pm 0,7$ \\
\hline MP67 & $71,2(67,3-73,6) \pm 2,1$ & $18,1(16,9-19,4) \pm 1,0$ \\
\hline MP69 & $70,9(66,0-75,2) \pm 3,4$ & $19,5(16,4-22,5) \pm 2,0$ \\
\hline MP70 & $71,0(63,4-78,5) \pm 4,0$ & $17,9(16,7-18,9) \pm 0,8$ \\
\hline MPBA & $68,9(59,5-74,0) \pm 5,1$ & $21,0(17,5-25,0) \pm 2,7$ \\
\hline MPAX & $71,1(66,6-74,8) \pm 2,4$ & $19,3(16,0-23.1) \pm 2,2$ \\
\hline MPTY & $71,0(68,6-74,6) \pm 2,1$ & $19,7(16,5-23,8) \pm 2,4$ \\
\hline
\end{tabular}

${ }^{\mathrm{a}}$ Média, ${ }^{\mathrm{b}}$ Valor mínimo, ${ }^{\mathrm{c}}$ Valor máximo, ${ }^{\mathrm{d}}$ Desvio-padrão

Brasil. A amplitude de variação de caracteres morfométricos em populações brasileiras desse nematóide, tais como, o comprimento do estilete, $\mathrm{V} \%$ e forma da cauda, é maior que em populações desse nematóide de outras regiões do mundo (Dasgupta et al., 1968; Lehman \& Inserra, 1989). A bifurcação da cauda em fêmeas jovens de $R$. reniformis ainda não havia sido relatada. 


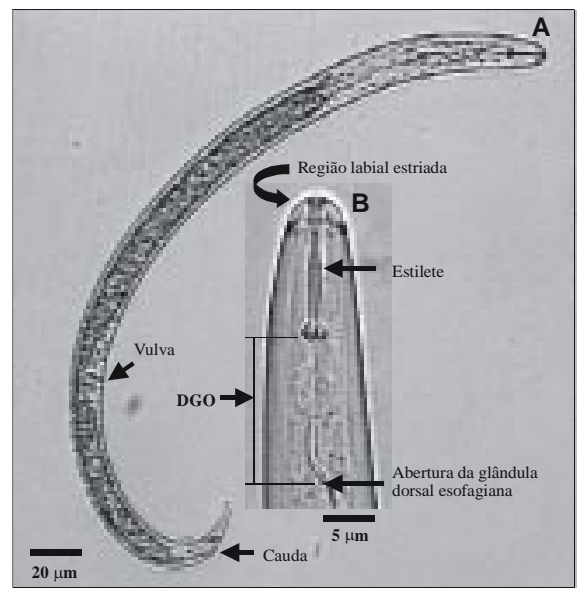

FIG. 3 - Fotomicrografias de fêmea vermiforme de Rotylenchulus reniformis. A) Fêmea inteira e B) Região anterior, mostrando estruturas de importância taxonômica.
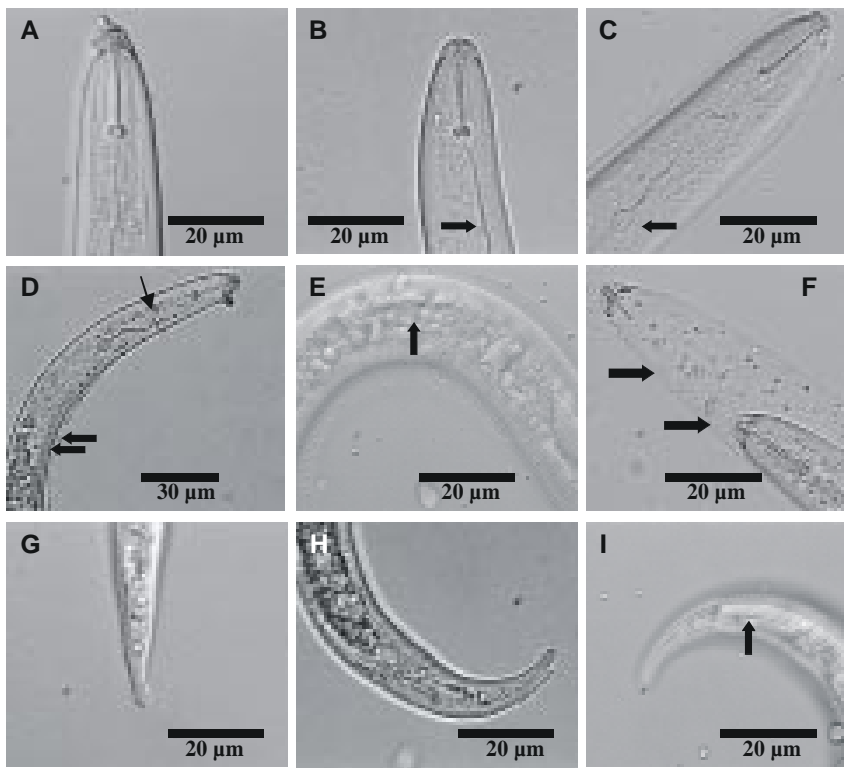

FIG. 4 - Fotomicrografias de fêmeas jovens de Rotylenchulus reniformis A) Região labial cônica. B) Região labial arredondada e abertura da glândula dorsal esofagiana (seta). C) Metacorpo com válvula esclerotizada (seta). D) Sobreposição ventral do esôfago sobre o intestino (setas) e abertura da glândula dorsal esofagiana (seta). E) Campo lateral com quatro incisuras (seta). F) Cutículas remanescentes de duas ecdises anteriores (setas). G e H) Variações na forma da cauda. I) Fasmídio (seta).

\section{REFERÊNCIAS BIBLIOGRÁFICAS}

BYRD, D.W.J.R., KIRKPATRICK, J. \& BARKER, K.R. An improved technique for clearing and staining plant tissues for detection of nematodes. Journal of Nematology 15:131-147. 1983.

DASGUPTA, D.R., RASKI, D.J. \& SHER, S.A. A revision of the genus Rotylenchulus Linford \& Oliveira, 1949. Proceedings of the Helminthological Society of Washington 35:169-92. 1968.

FORTUNER, R. A reappraisal of the Tylenchina (Nemata). 8. The family Hoplolaimidae Filip'ev, 1934. Revue de Nématologie 10:219232. 1987.

GERMANI, G. Caracteres mopho-biometriques de trois species ouest - africanes de Rotylenchulus Linford and Oliveira, 1940 (Nematoda - Tylenchida). Revue de Nématologie 1:241-250. 1978.

JATALA, P. Reniform and false root-knot nematodes, Rotylenchulus and Nacobbus spp. In: Nickle, W.R. (Ed.) Manual of agricultural nematology. New York. Marcel Dekker. 1991. pp.509-528.

JENKINS, W.R. A rapid centrifugal flotation technique for separating nematodes from soil. Plant Disease Reporter 48:692. 1964.

LEHMAN, P.S. \& INSERRA, R.N. Morphometric variation of Rotylenchulus parvus and Rotylenchulus reniformis populations in the southern United States. Soil and Crop Science Society of Florida Proceedings 49:220-226. 1990.

PASSOS, S.M.G. Algodão. Campinas: Instituto Campineiro de Ensino Agrícola. 1977.

ROBINSON, A.F., INSERRA, R.N., CASWELL-CHEN, E.P., VOVLAS, N. \& TROCCOLI, A. Rotylenchulus species: identification, distribution, host ranges, and crop plant resistance. Nematropica 27:127-180. 1997.

SANTOS, J.M. \& MAIA, A.S. A SEM improved technique for studying host-pathogen interactions of sedentary nematodes and for documentation of perineal patterns of Meloidogyne spp. Acta Microscópica 6:562-563. 1997.

SIDDIQI, M.R. Rotylenchulus reniformis. C.I.H. Descriptions of plant-parasitic nematodes. Set. 1, No. 5. Farnham Royal, UK: Commonwealth Agricultural Bureaux, 1972.

SIVAKUMAR, C.V. \& SESHADRI, A.R. Life history of the reniform nematode Rotylenchulus reniformis Linford and Oliveira, 1940. Journal of Nematology 1:7-20. 1971.

STARR, J.L. \& PAGE, S.L.J. Nematode parasites of cotton and other tropical fiber crops. In: Luc, M., Sikora, R.A. \& Bridge, J. (Eds.) Plant parasitic nematodes in subtropical and tropical agriculture. Wallingford: CAB International. 1990. pp.539-556.

VAN DEN BERG, E. Two new and one known species of the Tylenchoidea (Nemata) from Southern Africa. Phytophylactica 22:23-34. 1990. 